\title{
Immunotherapies for Neurological Manifestations in the Context of Systemic Autoimmunity
}

\author{
Eleni I. Kampylafka ${ }^{1}$ • Harry Alexopoulos ${ }^{1} \cdot$ Marinos C. Dalakas $^{1}$. \\ Athanasios G. Tzioufas ${ }^{1}$
}

Published online: 28 October 2015

(C) The American Society for Experimental NeuroTherapeutics, Inc. 2015

\begin{abstract}
Neurological involvement is relatively common in the majority of systemic autoimmune diseases and may lead to severe morbidity and mortality, if not promptly treated. Treatment options vary greatly, depending on the underlying systemic pathophysiology and the associated neurological symptoms. Selecting the appropriate therapeutic scheme is further complicated by the lack of definite therapeutic guidelines, the necessity to differentiate primary neurological syndromes from those related to the underlying systemic disease, and to sort out adverse neurological manifestations caused by immunosuppressants or the biological agents used to treat the primary disease. Immunotherapy is a sine qua non for treating most, if not all, neurological conditions presenting in the context of systemic autoimmunity. Specific agents include classical immune modulators such as corticosteroids, cyclophosphamide, intravenous immunoglobulin, and plasma exchange, as well as numerous biological therapies, for example antitumor necrosis factor agents and monoclonal antibodies that target various immune pathways such as B cells, cytokines, and co-stimulatory molecules. However, experience regarding the use of these agents in neurological complications of systemic diseases is mainly empirical or based on small uncontrolled studies and case series. The aim of this review is to present the state-of-the-art therapies applied in various neurological manifestations encountered in the context of systemic autoimmune
\end{abstract}

Electronic supplementary material The online version of this article (doi:10.1007/s13311-015-0393-3) contains supplementary material, which is available to authorized users.

Athanasios G. Tzioufas

agtzi@med.uoa.gr

1 Department of Pathophysiology, Faculty of Medicine, National and Kapodistrian University of Athens, Athens 11527, Greece diseases; evaluate all treatment options on the basis of existing guidelines; and compliment these data with our personal experience derived from a large number of patients.

Keywords Immunotherapies $\cdot$ Systemic autoimmune disease $\cdot$ Systemic lupus erythematosus · Arthritis . Vasculitis · Sjögren's syndrome

\section{Introduction}

Neurological involvement in the context of systemic autoimmunity may be devastating, making its prompt and effective management a sine qua non for the patients' survival and quality of life $[1,2]$. In the majority of systemic autoimmune disorders, central nervous system (CNS) manifestations can be attributed to various mechanisms, including ischemic vasculopathy, frank inflammatory vasculitis, cytokine-mediated diffuse inflammation, T-cell-mediated cytotoxicity, antineuronal autoantibodies, and CNS invasion by mass-like lesions. The induced symptoms may be either diffuse or focal $[2,3]$.

The aim of this article is to summarize the available information on neurological involvement in the context of systemic autoimmune diseases, evaluate treatment options based on guidelines and clinical studies, present our own clinicopathologic observations and therapeutic choices based on a large series of patients seen in our center for rheumatic and systemic autoimmune diseases, and discuss treatment-related neurological complications, particularly those caused by biological agents. Owing to the mechanistic diversity of the neurological complications and the lack of randomized trials, the information provided is not always evidence-based. However, our approach, which encompasses neurological, rheumatological, and immunological expertise, is expected to provide a state- 
of-the art overview on the characterization and management of these disorders.

\section{Concerns Over the Prevalence of Neurological Involvement in Systemic Autoimmunity}

Neurological involvement in the context of systemic autoimmunity is highly diverse, either between disorders or within the same disease (Table 1) [2, 3]. Description, incidence, and prevalence of neurological manifestations for each autoimmune syndrome varies greatly owing to a lack of consensus criteria regarding diagnosis, causality, and therapy, and the difficulties in determining whether a neurological manifestation is a primary event coexisting with the underlying disease or secondary due to systemic autoimmunity.

Systemic lupus erythematosus (SLE) is a typical example that illustrates the aforementioned issues. In 1999, the American College of Rheumatology proposed a panel of case definitions for neurological manifestations, including $12 \mathrm{CNS}$ and 9 peripheral nervous system (PNS) manifestations (Table 2) [4]. Over the ensuing years, however, significant diagnostic concerns evolved regarding specificity, with a wide prevalence ranging between $12 \%$ and $95 \%$ [5]. However, when "minor" or nondisease-specific events, such as headaches, mild cognitive dysfunction, or anxiety disorders, were

Table 1 Neurological manifestations in systemic autoimmune diseases

\begin{tabular}{|c|c|c|}
\hline Systemic autoimmune disease & CNS manifestations & PNS manifestations \\
\hline ANCA-positive vasculitides & $\begin{array}{l}\text { Stroke, subarachnoid hemorrhage, } \\
\text { meningeal involvement, diffuse } \\
\text { encephalopathy, headaches, } \\
\text { cognitive dysfunction, seizures, } \\
\text { ataxia }\end{array}$ & $\begin{array}{l}\text { Mononeuritis multiplex, distal symmetric } \\
\text { or asymmetric polyneuropathy, cranial } \\
\text { neuropathies }\end{array}$ \\
\hline Antiphospholipid syndrome & $\begin{array}{l}\text { Stroke, venous sinus occlusion, } \\
\text { seizures, MS-like disease, } \\
\text { movement disorders, migraine, } \\
\text { cognitive dysfunction, myelopathy, } \\
\text { optic neuropathy }\end{array}$ & $\begin{array}{l}\text { Peripheral axonal neuropathy, autonomic } \\
\text { disorders }\end{array}$ \\
\hline Behcet's syndrome & $\begin{array}{l}\text { Meningoencephalitis, headaches, } \\
\text { cognitive dysfunction, sensory } \\
\text { and motor deficits, psychosis, } \\
\text { seizures, ataxia, central venous } \\
\text { thrombosis, myelopathy, optic } \\
\text { neuropathy }\end{array}$ & $\begin{array}{l}\text { Sensory or sensorimotor axonal polyneuropathy, } \\
\text { mononeuritis multiplex, AIDP, cranial } \\
\text { neuropathies, autonomic disorders, myositis }\end{array}$ \\
\hline Giant cell arteritis & $\begin{array}{l}\text { Headaches, optic neuropathy and } \\
\text { visual disturbances, stroke, } \\
\text { cervical myelopathy }\end{array}$ & $\begin{array}{l}\text { Cranial neuropathies, cervical radiculopathies, } \\
\text { polyneuropathy, multiple mononeuropathy, } \\
\text { polymyalgia rheumatica }\end{array}$ \\
\hline Rheumatoid arthritis and seronegative arthritis & $\begin{array}{l}\text { Headaches, seizures, sensory and } \\
\text { motor dysfunction, cognitive } \\
\text { dysfunction, acute confusion, } \\
\text { emotional disturbances, myelopathy, } \\
\text { optic atrophy, cauda equina syndrome }\end{array}$ & $\begin{array}{l}\text { Entrapment neuropathies, mononeuritis multiplex, } \\
\text { sensory and sensorimotor neuropathy, } \\
\text { radiculopathies, autonomic disorders }\end{array}$ \\
\hline Systemic lupus erythematosus & $\begin{array}{l}\text { Epileptic seizures, stroke, chorea, } \\
\text { myelopathy, optic neuropathy, acute } \\
\text { confusional state, aseptic meningitis, } \\
\text { cognitive dysfunction, depression, } \\
\text { psychosis, anxiety disorders, headache, } \\
\text { demyelinating syndrome }\end{array}$ & $\begin{array}{l}\text { AIDP, autonomic disorders, mononeuropathy } \\
\text { simple/multiplex, myasthenia gravis, myositis, } \\
\text { cranial neuropathies, plexopathy, polyneuropathy }\end{array}$ \\
\hline Scleroderma & $\begin{array}{l}\text { Seizures, psychosis, depression, headaches, } \\
\text { movement disorders, myelopathy }\end{array}$ & $\begin{array}{l}\text { Entrapment neuropathies, multiple mononeuropathy, } \\
\text { peripheral sensorimotor, cranial neuropathies, } \\
\text { autonomic disorders, myositis }\end{array}$ \\
\hline Sjogren's syndrome & $\begin{array}{l}\text { Meningitis, meningoencephalitis, } \\
\text { MS-like disease, subacute encephalopathy, } \\
\text { seizures, cognitive dysfunction, } \\
\text { headaches, psychosis, chorea, motor } \\
\text { neuron disease, myelopathy, optic } \\
\text { neuropathy }\end{array}$ & $\begin{array}{l}\text { Sensory or sensorimotor polyneuropathy, cranial } \\
\text { neuropathies, mononeuritis multiplex, } \\
\text { ganglionopathy, polyradiculoneuropathy, } \\
\text { small-fiber neuropathy, autonomic disorders, } \\
\text { myositis }\end{array}$ \\
\hline Takayasu arteritis & $\begin{array}{l}\text { Headaches, stroke, visual disturbances, } \\
\text { intracranial haemorrhage }\end{array}$ & - \\
\hline
\end{tabular}

$\mathrm{CNS}=$ central nervous system; $\mathrm{PNS}=$ peripheral nervous system; $\mathrm{ANCA}=$ antineutrophil cytoplasmic antibody; $\mathrm{MS}=$ multiple sclerosis; $\mathrm{AIDP}=$ acute inflammatory demyelinating polyradiculoneuropathy (Guillain-Barré syndrome) 
Table 2 The American College of Rheumatology Nomenclature and Case Definitions for Neuropsychiatric Lupus Syndromes (1999)

\begin{tabular}{ll}
\hline Central nervous system & Peripheral nervous system \\
\hline Aseptic meningitis & Guillain-Barré syndrome \\
Cerebrovascular disease & Autonomic disorder \\
Demyelinating syndrome & Mononeuropathy simple/multiplex \\
Headache & Myasthenia gravis \\
Movement disorders (chorea) & Neuropathy cranial \\
Myelopathy & Plexopathy \\
Epileptic seizures & Polyneuropathy \\
Acute confusional state & \\
Anxiety disorders & \\
Cognitive dysfunction & \\
Mood disorders & \\
Psychosis & \\
\hline
\end{tabular}

excluded $[6,7]$, the prevalence range was estimated at $<30 \%$. The example of SLE can be applied to almost all systemic autoimmune disorders that present with neurological manifestations, apart from cases where the neurological event is attributed to a definitive nonimmune mechanism, for example spinal cord compression by bony structures as seen in rheumatoid and seronegative arthritis [8].

\section{Types of Neurological Involvement and the Role of Immunotherapy}

Immunosuppressive treatment still remains the major therapeutic choice for systemic autoimmune disorders aiming to reduce systemic inflammation and prevent permanent damage caused by the disease. Corticosteroids remain the mainstay of immunotherapy, either in high oral doses or intravenously during disease exacerbations, while lower oral doses are routinely used for maintenance treatment. Other conventional immunosuppressants, including methotrexate (MTX), azathioprine (AZA), cyclophosphamide, mycophenolate mofetil, and ciclosporin are variably applied $[9,10]$, while nonspecific immunomodulating therapies such as intravenous immunoglobulins (IVIg) and plasmapheresis are reserved for severe and refractory manifestations $[11,12]$. In the last 2 decades, the introduction of anti-tumor necrosis factor (anti-TNF) agents has been pivotal in treating inflammatory arthritis [13], leading to their off-label application in other autoimmune diseases, such as Behçet's disease (BD) and sarcoidosis $[14,15]$. Lastly, monoclonal antibodies targeting B cells (rituximab), inflammatory cytokines such as interleukin (IL)-6 and IL-1 $\beta$ (tocilizumab and canakinumab, respectively), or co-stimulatory molecules (abatacept) have expanded the therapeutic armamentarium. The efficacy of these agents has been demonstrated in clinical trials for some disorders, including belimumab for SLE (moderate disease without active neurological involvement) and tocilizumab for rheumatoid arthritis (RA) and systemic juvenile idiopathic arthritis [16, 17], but, for others, such as rituximab for SLE or tocilizumab for BD, their use remains off-label, based on noncontrolled studies or case reports $[18,19]$. The main indications, administration routes, and complications of biological agents used in systemic autoimmunity-related neurological manifestations are depicted in Table 3.

The main neurological manifestations that require immunotherapies include 1) autoimmune encephalopathy syndromes, presenting with symptoms such as acute confusion, epileptic seizures, psychosis, cognitive dysfunction, headaches, and major depression; 2) inflammatory vasculitis; 3) demyelinating manifestations of the CNS; 4) myelopathy due to demyelination, gray matter inflammation or ischemic lesions; 5) optic neuritis occurring as a single event or together with myelopathy in the context of neuromyelitis optica spectrum (NMO); 6) PNS involvement in the form of mononeuropathies, mononeuritis multiplex, cranial neuropathies, chronic inflammatory demyelinating polyradiculoneuropathy (CIDP), or autonomic neuropathies; and 7) inflammatory myopathies [2, 3, 5, 20, 21].

The strength of evidence for all applied treatments in patients with systemic autoimmune diseases is of great concern (Table 4) [22]. Recommendations and guidelines for the management of neurological complications are even more disconcerting, because in the vast majority of cases they have been based on nonrandomized trials, small noncontrolled studies, or entirely on expert opinion. Consequently, the treatment for the vast majority of neurological complications still remains empirical or relies on observational studies.

\section{Neurological Involvement in Distinct Systemic Autoimmune Diseases}

\section{SLE}

In SLE, a variety of pathogenetic mechanisms has been implicated, including ischemic vasculopathy, frank inflammatory vasculitis, diffuse inflammation mediated by cytokines, blood-brain barrier dysfunction, and sensitized T cells or antibodies reaching the CNS compartment. The neurological complications in SLE that require immunotherapies include the following.

Acute or Subacute Meningoencephalitis Presenting as Acute Confusional State Accompanied by Seizures, or Psychosis and Aseptic Meningitis

The latter may also present as an isolated manifestation $[1,23]$ associated with high disease activity. According to the 2010 
Table 3 Category of evidence and strength of statements for intervention studies (adapted from Bertsias and Boumpas [5])

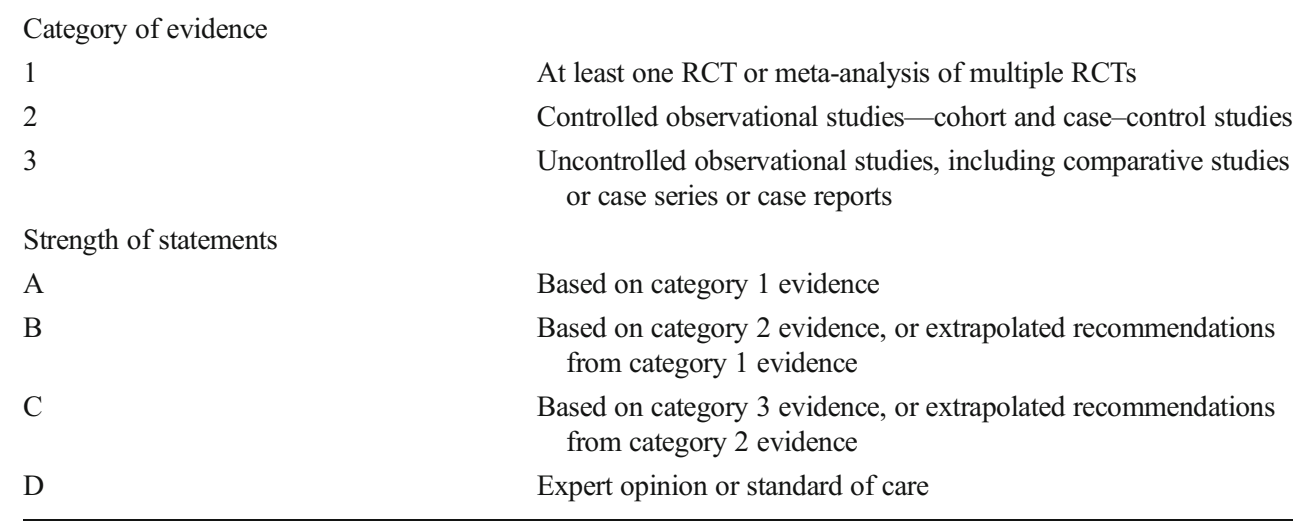

$\mathrm{RCT}=$ randomized controlled trial.

Adapted from Bertsias et al, Ann Rheum Dis, 2010
European League Against Rheumatism (EULAR) recommendations [22], aggressive immunosuppression, using intravenous pulses of steroids and cyclophosphamide is the treatment of choice for such acute events (grade of recommendation 1A and 2B) [22], along with symptomatic regimens depending on the overriding symptoms (i.e., anticonvulsants, antipsychotics, etc.; grade 3D) [22, 24]. In refractory cases, the proposed therapeutic schemes include IVIg, plasmapheresis, and B-cell depletion therapy with rituximab, based on small case series (grade 3D) [12, 25, 26]. The recently released SLEspecific anti-Blys/ BAFF monoclonal antibody belimumab has not been tested in SLE patients with CNS involvement and its therapeutic value remains uncertain [27]. The psychosis reported in 2.5-3.5\% of SLE must be distinguished from steroid-induced psychosis (see "Steroid-induced Psychosis and "Myopathy" section) or major depressive symptoms. Patients with true lupus psychosis may additionally require short-term treatment with neuroleptics.

Epileptic seizures are a common CNS manifestation, occurring in as much as $2-10 \%$ of patients, mainly associated with high disease activity and antiphospholipid antibodies [5, $23,28]$. Apart from symptomatic antiepileptic therapy, immunosuppression is indicated when high disease activity coexists or whenever there is suspicion of underlying inflammatory mechanisms (grade 3D); whether the proposed hydroxychloroquine has a protective effect (grade $2 \mathrm{C}$ ) remains to be determined [23].

\section{Progressive Cognitive Dysfunction not in the Context of Overt Encephalopathy}

This is mainly due to chronic cumulative lesions related to microvasculopathy [24]. Immunotherapy is applied only when changes are subacute or an autoimmune limbic encephalopathy is suspected (see above). Minor events with no clear underlying pathophysiology, such as headaches, mild depression, and cognitive dysfunction, require no immunotherapy and are treated with symptomatic regimens.

\section{Focal Ischemic Manifestations}

Focal ischemic manifestations, including strokes, which are the most common manifestation (2-10\% of the cases), and chorea $(0.6 \%)$, are treated symptomatically but require immunosuppression only in the context of concurrent high disease activity and signs of CNS inflammation [i.e., cerebrospinal fluid (CSF) lymphocytosis or antineuronal antibodies] (grade 3D) [22]. The main risk factors are cumulative damage attributed to the systemic disease and antiphospholipid antibodies [5, 28], necessitating therapy with anticoagulants or antiplatelet agents (grade 2C), along with adequate control of non-SLE-related risk factors. Dopamine antagonists may be used in persistent chorea (grade 3D) [22, 29].

\section{SLE Myelopathy}

SLE myelopathy, as an isolated event or with optic neuritis, affects $1-2 \%$ of patients and has 2 main patterns: acute inflammatory myelitis and ischemic myelopathy [1]. Inflammatory myelitis can be further divided depending on whether gray or white matter is primarily involved [30]. High disease activity is associated with gray matter dysfunction and overt inflammation, whereas antiphospholipid and NMO-IgG/ antiaquaporin 4 antibodies, along with lower disease activity, correlate with white matter dysfunction [30, 31]. Optic neuritis can occur without myelitis and it is either inflammatory or ischemic (associated with antiphospholipid antibody positivity) [5].

Treatment of SLE-related optic neuritis or myelitis consists of high-dose intravenous (IV) methylprednisolone and cyclophosphamide (grade 1A and 2A) [22]. Plasma exchange and rituximab are therapeutic options for refractory cases (grade 
Table 4 Biological agents used in neurological manifestations of systemic autoimmune diseases

\begin{tabular}{|c|c|c|c|}
\hline Biological agent & Indications & Route of administration & Major complications \\
\hline Anti-TNF agents & $\begin{array}{l}\text { - RA (vasculitis, pachymeningitis)* } \\
\text { - Takayasu } \\
\text { - Behçet's disease }\end{array}$ & $\begin{array}{l}\text { IV or SC (depending on the } \\
\text { specific agent administered) }\end{array}$ & $\begin{array}{l}\text { Infection } \\
\text { Demyelination } \\
\text { Malignancy } \\
\text { SLE or vasculitis-like syndromes } \\
\text { Pulmonary fibrosis } \\
\text { Pancytopenia }\end{array}$ \\
\hline Rituximab & $\begin{array}{l}\text { - SLE (meningoencephalitis, seizures, psychosis, } \\
\text { acute confusional state, optic neuritis, myelitis, myositis) } \\
\text { - APS } \\
\text { - RA (pachymeningitis) } \\
\text { - pSS (CNS involvement, ganglionopathy) } \\
\text { - Takayasu arteritis } \\
\text { - ANCA-associated vasculitides }\end{array}$ & IV & $\begin{array}{l}\text { Infection } \\
\text { Cytopenias } \\
\text { Hepatitis B reactivation } \\
\text { Myocardial infarction, arrhythmias } \\
\text { Bronchiolitis, pneumonitis }\end{array}$ \\
\hline Tocilizumab & $\begin{array}{l}\text { - Inflammatory Myopathies } \\
\text { - RA (peripheral neuropathies) } \\
\text { - Takayasu arteritis } \\
\text { - Behçet's disease }\end{array}$ & IV, SC & $\begin{array}{l}\text { Infection } \\
\text { Cytopenias } \\
\text { Increased liver enzymes } \\
\text { Malignancy } \\
\text { Increased cholesterol } \\
\text { Bowel perforation }\end{array}$ \\
\hline Abatacept & $\begin{array}{l}\text { - RA (peripheral neuropathies) } \\
\text { - ANCA-associated vasculitides* }\end{array}$ & IV, SC & $\begin{array}{l}\text { Infection } \\
\text { Malignancy }\end{array}$ \\
\hline Anakinra & $\begin{array}{l}\text { - Inflammatory Myopathies } \\
\text { - Behçet's disease }\end{array}$ & $\mathrm{SC}$ & $\begin{array}{l}\text { Infection } \\
\text { Cytopenias }\end{array}$ \\
\hline
\end{tabular}

$\mathrm{TNF}=$ tumor necrosis factor; RA=rheumatoid arthritis; IV=intravenous; $\mathrm{SC}=$ subcutaneous; $\mathrm{SLE}=$ systemic lupus erthyematosus; APS= antiphospholipid syndrome; RA=rheumatoid arthritis; pSS=primary Sjögren's syndrome; $C N S=$ central nervous syndrome; ANCA=antineutrophil cytoplasmic antibody

*Inconclusive results

3D) $[12,18,32]$, while anticoagulation or antiplatelet agents can be considered in the case of antiphospholipid antibody positivity, or whenever ischemic damage is suspected (grade 2B) [33].

\section{Peripheral Neuropathies}

Peripheral neuropathies occur in 2-18\% of patients with SLE according to most studies; the most common neuropathy is a symmetric axonal neuropathy, seen in $2-3 \%$ of patients, followed by mononeuropathy multiplex, cranial neuropathies, plexopathies, and CIDP (all <1 \%) [1, 5, 34]. Mononeuritis multiplex is thought to be due to vasculitis of the vasa nervorum, although we have rarely seen overt vasculitis in the nerve biopsies we have performed. Cranial neuropathies, if associated with antiphospholipid antibodies, are considered to be ischemic or vasculitic in origin $[35,36]$, while in cases of central venous thrombosis they are due to intracranial hypertension. In our experience (MCD), cranial neuropathies such as Bell's palsy or trigeminal neuralgia are not infrequently seen with all systemic rheumatic diseases. Steroids, alone or combined with IVIg, or plasmapheresis are the best treatment options for CIDP (grade 1A) [37, 38]. IV cyclophosphamide is the preferable treatment in vasculitic neuropathy (grade 1A) $[22,39,40]$.
In our experience, the most common neuropathy in SLE is a painful small fiber sensory neuropathy, affecting the small unmyelinated nerve fibers. In such cases, a skin biopsy assessing epidermal small fiber density could be diagnostic $[22,41]$. Whether in some of these patients the small fiber neuropathy has an autoimmune etiology remains to be determined.

\section{Inflammatory Myositis}

Inflammatory myositis can rarely occur in patients with SLE $[2,4]$, and treatment options are practically the same as for all autoimmune inflammatory myopathies [2]. First-line treatment includes high-dose oral or IV steroids, followed by steroid-sparing agents such as AZA, MTX, ciclosporin, or mycophenolate mofetil (grade 3C and 3D) [42]. In refractory cases, administration of IVIg or rituximab may be helpful (grade 1A and 1B, respectively) [2, 11, 42, 43]. Ongoing trials are currently evaluating the efficacy of biological agents such as tocilizumab, anakinra, gevokizumab, and alemtuzumab in inflammatory muscle diseases [42], and these agents may as well be tested on patients with an underlying systemic autoimmune disease. Finally, myasthenia gravis, a rare occurrence in the context of SLE, is treated according to the respective myasthenia gravis guidelines [44]. 


\section{Antiphospholipid Syndrome}

Patients with antiphospholipid syndrome (APS) can present with strokes, transient ischemic attacks, a multiple sclerosis (MS)-like picture, seizures, movement disorders (i.e., chorea, ataxia, dyskinesias), migraine, and cognitive dysfunction [3, $21,45]$. Overt encephalopathy and venous sinus occlusions are rare events, mainly occurring in the context of catastrophic APS, which presents in about $1 \%$ of patients with APS [21]. Acute myelopathy and optic neuropathy can also rarely occur, occasionally in the context of an NMO spectrum disorder [3, 45-47]. The main pathogenetic mechanism is vasculopathy and thrombosis, mediated by endothelial, platelet, and complement activation. A direct interaction between antiphospholipid antibodies and neuronal membrane antigens has also been demonstrated and may play a role in some APS-related manifestations such as seizures and chorea [21, 45, 48].

Anticoagulation is the main treatment in these patients, according to the recent recommendations for antiphospholipid positive patients (nongraded, owing to lack of consensus) [49, 50], while antiplatelet agents are also administered as secondary prevention for thrombosis. However, in severe cases of CNS involvement, immunosuppression is strongly indicated, according to the international consensus for catastrophic APS. Immunosuppressive agents include high-dose oral or IV pulses of glucocorticoids and cyclophosphamide, plasma exchange, and IVIg (grade 3C) [21, 51]. Finally, some reports support the successful treatment of such cases with rituximab (grade 3D) [52].

\section{Inflammatory Arthritis}

Inflammatory brain involvement has been described in the context of RA but is rather rare. This involvement includes vasculitis, leading to hemorrhage or strokes, rheumatoid leptomeningitis or pachymeningitis, and rheumatoid nodule formation, whereas normal-pressure hydrocephalus has also been reported [53-58]. The above can lead to a variety of symptoms, including headaches, seizures, sensory, and motor difficulties, cognitive dysfunction, acute confusion, and emotional disturbances, depending on the brain structures involved [8].

Mortality in the context of these manifestations can be high [59]; therefore, immunosuppression by high doses of steroids may not be sufficient and a combination with other agents, especially cyclophosphamide, is recommended [60, 61]. Even though anti-TNF agents are highly effective in RA treatment, a single report of infliximab administration in a patient with RA pachymeningitis led to a relapse [62], while in another case report, rituximab was efficient in RA pachymeningitis [58]. Further, MTX has been reported to cause rheumatoid nodulosis on the meninges [63]. Our view, therefore, is that biological agents should be cautiously used in patients with
RA who have already exhibited meningeal lesions, and these potential treatment-related adverse reactions should be taken into consideration in the differential diagnosis of these manifestations.

The spinal cord in RA is mainly affected due to external compression, resulting either from atlantoaxial or subaxial subluxation [8], or less commonly from rheumatoid nodules and epidural lipomatosis [2, 64]. Also, in seronegative inflammatory arthritides, such as psoriatic arthritis and ankylosing spondylarthritis (AS), atlantoaxial subluxation or spinal cord impingement can occur at many levels, leading to sensory and motor deficits $[65,66]$.

Treatment in cases of external compression of the spinal cord is mainly surgical but IV steroids should be administered to reduce inflammation in cases of acute cord compression (grade 3D) [67]. The role of immunosuppressants in these cases is unclear. One patient with cauda equina syndrome secondary to AS was successfully treated with infliximab [68], while in another case of acute transverse myelitis in a patient with psoriatic arthritis, a high dose of methylprednisolone resulted in symptom amelioration [69].

Peripheral neuropathies have been reported in 20-60\% of patients with RA [8], but in our experience this is an overinflated figure, mainly due to neuropathies caused by external compression. Thus, neuropathies can be compressive, causing carpal tunnel syndrome, posterior interosseous nerve palsy, and cubital tunnel syndrome [3, 8], or noncompressive; the latter are seen in up to $20 \%$ of patients with RA and present as mononeuritis multiplex (presumably due to vasculitis), distal sensory and sensorimotor axonal neuropathy [3, 8], or smallfiber sensory neuropathy. In other inflammatory arthritis, including psoriatic arthritis and AS, entrapment neuropathies can also occur; in the case of AS these are mainly radiculopathies $[70,71]$.

Treatment of entrapment neuropathies includes modification of activities, splints, topical steroid injections, and surgical treatment [2]. Mononeuritis multiplex is treated as a vasculitis with high-dose IV methylprednisolone and cyclophosphamide [72]. Whether anti-TNF agents are helpful remains unclear; although there are cases of successful treatment of refractory rheumatoid vasculitis [73, 74], there is also increased incidence of anti-TNF agent-induced peripheral neuropathy [75]. As we have observed demyelinating neuropathies caused by these agents, we do not recommend them in cases of already existing neuropathy. Other therapies that have shown efficacy in small noncontrolled studies or case reports are tocilizumab, anakinra, abatacept, IVIg, and plasmapheresis [76-79].

\section{Sjögren's Syndrome}

CNS involvement is a rare manifestation in primary Sjögren's syndrome (pSS) [80], and, in the majority of cases, is due to 
vasculopathy with endothelial dysfunction, leading to small infarcts or microaneurysms [3, 81]. Transverse myelitis has also been described in patients with pSS [3, 82, 83], and in a small percentage it may be accompanied by brain MS-like lesions or by optic neuritis making, at times, the distinction from a primary demyelinating disease such as MS or NMO rather difficult $[31,80]$. The meninges can also be affected, alone or in the context of meningoencephalitis [84], while in some cases a subacute encephalopathy presenting with memory loss, cognitive dysfunction, visual disturbances, and reduced concentration and attention has been noted [80]. Symptoms such as seizures, headaches, psychiatric disturbances, and cognitive dysfunction have also been described but their true prevalence and association with the underlying syndrome is questionable $[3,82]$. Isolated cases of optic neuropathy, chorea, and motor neuron syndromes can also exist [82, 83], but there does not appear to be any relationship or pathogenetic mechanism with the primary disease.

Treatment is similar to CNS lupus and mainly consists of immunosuppressive agents (high oral dose or IV pulse steroids, cyclophosphamide, AZA, mycophenolate mofetil) and possibly IVIg and rituximab [80, 85-88]. All these treatment options are, apart from our own experience, mostly documented in small case series.

Peripheral neuropathies are well documented in pSS, even though their prevalence varies greatly among studies (ranging from $2 \%$ to $60 \%$ ) $[83,89,90]$. Some studies have found that symmetric axonal sensory or sensorimotor polyneuropathy is the most common form of neuropathy (34.0\%), followed by cranial neuropathies $(19.5 \%)$, multiple mononeuropathies $(8.5 \%)$, ganglionopathies $(<5 \%)$, and CIDP (1.3\%) [20, $82,90]$. In our large series of patients, as well as in other studies, small fiber sensory neuropathy was the most common neuropathy, while demyelinating neuropathies were the rarest [20, 41, 90, 91].

Ganglionopathy causing sensory ataxic neuropathy is the most specific and severe form of peripheral neuropathy in $\mathrm{pSS}$, and, although rare, it is seen more frequently in pSS than in any other rheumatic disease. It presents with impaired kinesthetic awareness and proprioception, and leads to severe sensory ataxia with pseudoathetotic hand movements due to involvement of large ganglionic neurons [92]. A small case series reports successful management with IVIg (grade 3D) [93], while treatment with rituximab, plasmapheresis, infliximab, and interferon (IFN)- $\alpha$ were encouraging in other series (grade 3D) [94-97]. In our experience, this is a difficult entity to treat and quite disabling. However, when therapy is initiated early and before extensive ganglionic damage has occurred, there is possibility of improvement, hence the reason for early diagnosis and aggressive immunotherapy during this early narrow window (MCD, personal observations).

Multiple mononeuropathies can be either of vasculitic origin or due to other mechanisms [20]. Vasculitic neuropathies are rare $(0-5 \%)$, and they usually present in the context of pSS with extraglandular manifestations, such as purpura, or cryoglobulinemia $[82,98]$. However, when of vasculitic origin, multiple mononeuropathies have the best response to immunotherapies, such as steroids and cyclophosphamide [82, 99], followed by maintenance treatment preferably with mycophenolate mofetil. Axonal sensorimotor neuropathies have also been associated with extraglandular pSS [89, 100] and although treatment is similar to that of multiple mononeuropathies (grade 3D) [101], the results are, in our experience, disappointing. In nonvasculitis-related neuropathies, the efficacy of immunosuppression is expected to be rather low [101], and most clinicians apply symptomatic therapy $[20,91]$.

Small-fiber neuropathy is the most common sensory neuropathy in pSS (5-10\%) [20], albeit underestimated in many studies. The main symptom is pain; therefore, treatment is symptomatic as recommended by the European Federation of Neurological Societies' guidelines for neuropathic pain [102], with agents such as carbamazepine, gabapentin, and pregabalin (grade 1A). Tricyclic antidepressants may exacerbate sicca symptoms [103], while no immunotherapy has been particularly effective (steroids, IVIg, anti-TNF, or rituximab) [20, 88, 104, 105]. Similar treatment options are available for the most common cranial neuropathy in pSS, trigeminal neuropathy $[98,106]$. The possibility that some small-fiber neuropathies have an immune component is being currently explored and discussed by Oaklander. Finally, demyelinating neuropathies in the form of CIDP are rare in patients with pSS [98], but if they occur, treatment is similar to classical CIDP with corticosteroids, plasmapheresis or IVIg.

\section{Scleroderma}

Brain involvement in patients with scleroderma is practically described in the "coup de sabre" variant, mainly as complex partial epileptic seizures, accompanied by brain lesions ipsilateral to the skin lesions. Other associated symptoms are psychiatric disturbances and depression [107]. Brain lesions include focal subcortical calcifications, meningocortical alterations, white matter lesions, and gray matter atrophy [2, 108]. Whether the exact underlying mechanism of these lesions is autoimmune or vascular is currently unknown. More complex manifestations, such as cognitive dysfunction, headaches, myokymias, dystonia, and CNS vasculitis can occur, but mainly in the context of Parry Romberg syndrome (or hemifacial atrophy), which is considered a "coup de sabre" variant [2, 109].

Treatment remains empirical, and immunotherapy with steroids, cyclophosphamide, MTX, ciclosporin, IFN- $\gamma$, and Dpenicillamine is proposed by some studies but mainly for the treatment of aggressive skin and bone destruction (grade 3D) $[107,110,111]$. The effect of the abovementioned treatments 
in neurological involvement remains to be clarified. Spinal cord involvement due to ectopical calcinosis has been observed in only a few cases [112]. In cases where concurrent antiaquaporin 4-positive disease is present, treatment is according to the recommendations of the Neuromyelitis Optica Study Group [113].

Similarly to pSS, multiple mononeuropathies, peripheral sensorimotor neuropathy, autonomic nervous system dysfunction, and cranial neuropathies (mainly trigeminal) have been described in patients with systemic and localized scleroderma [107]. Proposed immunotherapies remain empirical like those in pSS, and include steroids, cyclophosphamide, AZA mycophenolate mofetil, and IVIg, based on a case-by-case evaluation (grade 3D) [107].

\section{Vasculitides}

Systemic vasculitides comprise a broad spectrum of disorders [114], which can affect different types of vessels, and neurological involvement is a common manifestation [3]. PNS involvement in systemic vasculitides is caused by ischemic occlusion of the vasa nervorum [115]. CNS involvement is more diverse and can be due to frank vasculitis, granuloma formation, or ischemic damage due to occlusion of extracranial vessels [115].

\section{Giant Cell Arteritis}

Giant cell arteritis (GCA) is the most common form of primary vasculitis and affects people $>50$ years of age [115]. Affected arteries include all the branches of the external carotid artery, namely the superficial temporal artery, the occipital artery, the facial and lingual artery, and the intraorbital branches [116]. Headaches and optic disturbances are the most common neurological manifestations. Amaurosis fugax, diplopia, and eye pain (up to $70 \%$ of cases) are mainly caused by anterior ischemic optic neuropathy and, if left untreated, they can lead to permanent visual loss $[2,115]$.

Polymyalgia rheumatica is another major feature of GCA, which occurs in approximately $50 \%$ of patients with GCA. Its main clinical manifestations are pain, morning stiffness, and weakness of the shoulder and pelvic area, whereas other symptoms, such as distal muscle involvement and nonerosive arthritis, are less frequent. However, it should be noted that polymyalgia rheumatica can be a discrete clinical syndrome, occurring without concurrent GCA [117].

Temporal artery biopsy is the gold standard for GCA diagnosis. The main histological lesions are vasculitic with predominant mononuclear cell infiltration or granulomatous inflammation, while multinucleated giant cells are also frequently observed [118]. However, temporal artery biopsy can be negative in about $10-20 \%$ of patients. Results could be either false negative, owing to the patchy involvement of the temporal arteries or to corticosteroid treatment, or true negative in those patients whose temporal arteries are not involved [117]. Finally, some studies have emphasized the possibility of varicella zoster virus infection, proven by temporal artery biopsy, which could mimic GCA symptoms [119], while in 1 patient varicella zoster virus infection was found in biopsy specimens diagnostic for GCA, thus implying a possible correlation between the two entities [120].

The recent British Society for Rheumatology (BSR) and British Health Professionals in Rheumatology (BSR and BHPR) guidelines for GCA management and EULAR recommendations for the management of large vessel vasculitides provide a thorough description of available induction and maintenance treatment options [121, 122]. Initial treatment consists of high oral dose steroids, which must be slowly tapered over months (grade 3C). In cases of severe ocular or cerebral involvement, treatment can be initiated by IV pulse steroids (500 mg-1gr/day for 3 days) [121]. Treatment with oral steroids is usually maintained for at least $2-3$ years.

\section{Takayasu Arteritis}

Takayasu arteritis affects the aorta and its branches and can also cause neurological symptoms (60-80\% in most series) [123]. These include headaches, dizziness, amaurosis, diplopia, strokes, and transient ischemic attacks. Ischemic myelopathy and cranial nerve involvement are very rare complications $[124,125]$. Large-vessel strokes can cause high morbidity and mortality $[2,3]$, and they are mainly caused by emboli from extracranial branches, but intracranial thrombosis or haemorrhage can also occur [115].

Takayasu arteritis is usually treated similarly to GCA, with high-oral dose steroids $(1 \mathrm{mg} / \mathrm{kg} /$ day $)$, followed by slow tapering and steroid-sparing agents, such as MTX, AZA, and cyclophosphamide (grade 3C) [122]. An open-label study and a retrospective review, along with some case reports and series, have shown promising results of anti-TNF treatment, but randomized trials are still lacking [126, 127]. Some case series have also proposed tocilizumab and rituximab as efficacious agents $[128,129]$.

\section{Antineutrophil Cytoplasmic Antibody-positive Vasculitides}

The antineutrophil cytoplasmic antibody (ANCA)-positive vasculitides include granulomatosis with polyangiitis (GPA), microscopic polyangiitis, and Churg-Strauss syndrome. CNS involvement in these disorders is not very common, accounting for not more than $10 \%$ in most studies $[115,130]$.

In GPA, 2 CNS inflammatory patterns exist, namely the granulomatous (either intracranial or due to invasion from extracranial sites) and the vasculitic, leading to pachymeningitis, ischemic and haemorrhagic lesions, and hypophyseal dysfunction [131]. Associated symptoms include 
headaches, sensory and motor deficits, cognitive dysfunction, seizures, and ataxia, depending on the affected brain areas [115], while spinal cord and ocular involvement rarely occur [131, 132].

Peripheral neuropathies are a very common manifestation of ANCA-positive vasculitides presenting in about $7-58 \%$ of patients with GPA and microscopic polyangiitis and 10-80\% of patients with CSS s $[115,133]$. The main forms of PNS involvement are, in descending order, mononeuritis multiplex, distal symmetric or asymmetric polyneuropathy, and cranial neuropathies [2, 131].

The EULAR, BSR, and BHPR guidelines highly recommend the use of immunosuppression in patients with ANCApositive vasculitides $[39,40]$, which can also be applied in neurological manifestations of the disease. Nerve biopsy is also highly recommended.

Induction treatment mainly consists of high-dose steroids and cyclophosphamide (grade 1A) [39, 40], while in the most recent BSR and BHPR criteria, rituximab is considered to be an equal alternative for induction treatment, both at initial presentation and in refractory cases (grade 1A and 1B) [40]. Noninferiority of rituximab over cyclophosphamide was proven in the RAVE trial, a multicenter, randomized, double-blind, noninferiority study (grade 1A) [134], and it has also shown efficacy in a few patients with neurological involvement $[135,136]$.

Maintenance therapy includes low-dose oral steroids and immunosuppressants such as AZA (grade 1A), leflunomide (grade 1B), MTX (grade 2B), and mycophenolate mofetil (grade 3C) [130, 131]. Moreover, rituximab can be also used as maintenance therapy but the level of evidence is low (grade 3C). Finally, studies including biological agents such as etanercept, adalimumab, abatacept, altemtuzumab, and mepolizumab either did not include patients with neurological involvement, or the results were inconclusive [137-139].

\section{Behçet's Disease (BD)}

The frequency of neurological involvement in BD varies greatly $(1.3-59.0 \%)[140,141]$, and CNS involvement can be either parenchymal or vascular "neuro-BD" [142]. However, in some studies, up to $20 \%$ of patients can present with a combination of the 2 forms [143, 144].

In the parenchymal form, the main feature is meningoencephalitis, characterized by brain inflammatory infiltrates and neuronal damage. This inflammatory perivasculitis may affect practically all areas of the brain, whereas inflammatory changes are also observed in the CSF. Clinical manifestations mainly include headaches, cognitive dysfunction, sensory and motor deficits, and psychosis, and, less commonly, seizures, ataxia, and extrapyramidal manifestations [140, 142, 145]. Transverse myelitis may also occur in the context of parenchymal neuro-BD (10\% of total neuro-BD cases), while isolated myelitis is rather uncommon. Isolated optic neuropathy is also very rare $(<1 \%)[142]$.

In nonparenchymal neuro-BD (16-20\% of total cases), vascular complications mainly involve large veins causing central venous thrombosis $(80 \%)$. Arteries are less commonly involved. Seizures may occur owing to central venous thrombosis, but haemorrhage is uncommon [146].

The diagnosis of neuro-BD is mainly clinical, as no specific diagnostic criteria, laboratory, and neuroimaging tests exist [142]. Further, in the vast majority of cases, systemic features of the disease precede the occurrence of neurological manifestations by several years $[145,147]$. Therefore, a high suspicion for neuro-BD should be raised in patients with established disease that present with any of the clinical or neuroimaging manifestations mentioned above.

No controlled trials exist for neuro-BD treatment. The 2008 EULAR recommendations for the management of BD mainly advocated the administration of IV corticosteroid pulses, usually in combination with other immunosuppressants, such as IV cyclophosphamide (750 mg-1gr/4 weeks), AZA, and MTX [148-151]. Some researchers propose steroid treatment on the first attack and withholding of further immunosuppression until a relapse occurs [142]. Spontaneous resolution has also been described [152].

IFN- $\alpha$, as well as the newer anti-TNF agents infliximab, adalimumab, and etanercept, have also been used successfully [153-156], while combination therapy with anti-TNF agents and conventional immunosuppression may be more effective [157]. Thus, official EULAR recommendations propose their use for refractory cases (grade 3C and 3D) [150]. Additionally, recently published small case series of patients with $\mathrm{BD}$ treated with tocilizumab and anakinra also include some patients with neuro-BD, and the results were encouraging [19, 158].

PNS involvement is very rare. It has been described in isolated case reports and series of patients, and includes sensory or sensorimotor axonal polyneuropathy, mononeuritis multiplex, acute inflammatory demyelinating polyradiculoneuropathy, isolated cranial neuropathies, ANS dysfunction, and subclinical nerve conduction abnormalities [147, 159-161]. Myositis is also extremely rare [142]. Owing to the rarity of these syndromes, no specific treatment guidelines exist.

\section{Issues Concerning Neurological Adverse Reactions of Long-term Immunosuppression}

\section{Steroid-induced Psychosis and "Myopathy"}

Steroids can induce acute psychosis or depression, especially when administered in doses $>1 \mathrm{mg} / \mathrm{kg} /$ day [162]. Therefore, in patients with systemic autoimmune disorders such as SLE or $\mathrm{BD}$ where psychosis may be a disease-related manifestation, a serious diagnostic and therapeutic challenge often arises. 
Steroid-induced psychosis is arguably rare and usually resolves after steroid discontinuation, but adjunctive antipsychotic treatment may be required in those cases that steroids seem to be the main culprit [163].

Steroids have also been thought to cause mild "myopathic weakness" and muscle atrophy, either acutely in patients treated with high-dose glucocorticoids or chronically, due to muscle catabolism and subsequent atrophy [164]. We believe that steroid-induced myopathy is a misnomer because steroids do not cause a destructive myopathy but only atrophy of type II muscle fibers; thus, it can be best described as steroid atrophy [165]. With the standard doses of prednisone or methylprednisolone we very rarely see steroid-induced weakness, especially in physically active patients and, in our opinion, this diagnosis has been used disproportionately in clinical practice (MCD). The main steroid that often causes muscle weakness is dexamethasone as used for brain edema, especially in patients with cancer. Nevertheless, the possibility of "myopathic weakness" does exist most often in immobilized or poorly mobilized patients who receive high daily doses and in patients who have a pre-existing, often severe, neuromuscular or systemic disorder. When in this setting, muscle weakness presents subacutely and steroid-induced atrophy should be excluded, especially when inflammatory myositis is in the differential diagnosis; in steroid-induced atrophic weakness there is absence of inflammatory markers and muscle enzyme elevation. In such cases, discontinuation or reduction of corticosteroids along with physical therapy improve muscle strength [166]. Proper tapering of steroids and the use of steroid-sparing immunosuppressants, along with a concurrent exercise program, are essential to prevent steroid-induced atrophic weakness.

\section{Posterior Reversible Encephalopathy Syndrome}

Posterior reversible encephalopathy syndrome (PRES) in a clinicoradiological entity caused by subcortical vasogenic edema, which leads to symptoms such as headaches, altered consciousness, seizures, and visual disturbances [167]. It can occur as a result of conditions such as eclampsia, hypertensive encephalopathy, and intense immunosuppression [168]. Patients with SLE and systemic vasculitis s have been reported to present with PRES [169], and a distinction between 2 subtypes of PRES in SLE, inflammatory and hypertensive, has been proposed [170].

PRES should be intensively treated in order to avoid relapses or permanent damage. Lowering and adequate monitoring of blood pressure is a sine qua non for all cases, while epileptic seizures should preferably be treated with rapidly effective IV agents. Removal of the underlying cause is necessary [167]. As hypertensive and immunosuppression related PRES is more common, patients with SLE and vasculitis with relevant CNS symptoms should be carefully evaluated. Often, escalation of immunosuppression can aggravate symptoms instead of resolving them [171]. However, in patients with SLE with high disease activity, a reduction of immunosuppression is usually not advocated, as the participation of inflammatory mechanisms is highly likely $[168,172]$.

\section{Progressive Multifocal Leukoencephalopathy}

Progressive multifocal leukoencephalopathy (PML) is an opportunistic demyelinating infection of the CNS [173]. The disorder almost invariably affects immunosuppressed patients, in particular those with impaired T-cell responses [174]. Until 1980 PML was an extraordinarily rare condition; the incidence changed as AIDS became epidemic and PML became a prominent opportunistic CNS infection in patients infected with HIV [175]. In the last few years there has been a surge of cases of and clinical interest in PML. This is owing to the association of PML with monoclonal and other newer immunosuppressive agents, including natalizumab, efalizumab, rituximab, mycophenolate mofetil, etanercept, and leflunomide [176-181].

In the vast majority of patients PML begins insidiously. Initial symptoms and signs are commonly indicative of focal cerebral involvement and may include alterations in personality, changes in intellect, focal weakness, difficulty with motor skills, or sensory loss. Visual abnormalities occur in $50 \%$ of patients. Occasionally, PML begins with signs of brainstem or cerebellar involvement; these may include abnormalities of eye movements, difficulties with phonation or swallowing, and ataxia $[173,182]$.

The causative agent of PML is the human polyomavirus $\mathrm{JCV}$, a ubiquitous human agent. JCV is an nonenveloped double-stranded DNA virus. The overall seroprevalence of anti-JCV antibodies is approximately $56 \%$ and the initial infection does not normally cause clinical disease [183]. Following initial infection, the virus persists in kidneys and in other tissues, including the brain. In immunologically normal patients this JCV persistence only results in recurrent episodes of asymptomatic viruria [184].

The factors that give rise to clinical PML have not been fully defined. It has been shown that most normal individuals have circulating cytotoxic T lymphocytes specific for JCV, which are crucial for PML containment [185]. Following natalizumab treatment, the drug alters T-cell-mediated immune surveillance, therefore allowing reactivation of JCV infection and PML development [186]. It has been shown that the CSF of patients treated with natalizumab contains not only reduced numbers of CD4+ and CD8+ T cells, but also reduced numbers of CD10+ B lymphocytes and CD138+ plasma cells compared with controls [182]. In patients with PML in the setting of natalizumab treatment, therapy involves removal of the monoclonal by plasma exchange, with or without accompanying immunoabsorption therapy. In both HIV-infected and iatrogenically immunosuppressed patients, restoration of 
immune function may result in immune reconstitution inflammatory syndrome [187].

In a recent study in the US, the national frequency of PML among patients with rheumatic diseases was estimated. A $20 \%$ sample of all hospital discharges, weighted to represent the entire US inpatient population, was analyzed. As expected, the vast majority of PML cases ( $82 \%$ ) were HIV-associated. In total, $0.44 \%$ of cases were SLE-associated, $0.25 \%$ of cases were RA-associated, and $0.26 \%$ were associated with other connective tissue disorders. For SLE, excluding other risk factors, it amounts to a rate of 4 cases per 100,000 discharges compared with a rate of 0.2 cases per 100,000 discharges in the general population [188]. This leads to the conclusion that patients with SLE are at a higher risk of developing PML. In this regard, it is interesting that CD4+ lymphopenia has been noted in many patients with rheumatic diseases, particularly in patients with SLE. Lack of CD4+ cells may lead to dysregulation in CTLs, which are necessary for JCV containment [189]. Lymphopenia has also been observed after treatment with several immunosuppressive therapies, suggesting that some of the treatments patients with SLE receive may be responsible for the increased incidence of PML [127].

\section{CNS and PNS Demyelination caused by anti-TNF Agents}

Demyelinating CNS and PNS disorders, following treatment with anti-TNF agents, have been described in many clinical studies and case series [190-195]. However, contradictory reports do exist; a prospective study in patients who had undergone neurological examination and neuroimaging studies before anti-TNF treatment initiation showed that the frequency of demyelination due to anti-TNF treatment is rather low [196].

TNF- $\alpha$ has also been implicated as a pathogenetic factor in MS. This inconsistency could be explained by the existence of 2 TNF receptors, TNFR1 and TNFR2, which mediate demyelination and remyelination, respectively [197]. As anti-TNF agents used in systemic autoimmune diseases are not specific for TNFR1, their administration could, indeed, induce such phenomenology. Overall, in patients with a history of MS, CIDP, or other demyelinating diseases, TNF inhibitors should be avoided, and patients receiving these agents should be closely monitored for the onset of neurological manifestations [198]. In our clinic, we have seen and followed 2 patients who developed multiple mononeuritis multiplex and CIDP after anti-TNF inhibitors requiring treatment with IVIg and rituximab.

\section{Conclusion}

Neurological involvement in systemic autoimmune diseases comprises many different syndromes and specific manifestations. Further research is needed to determine the etiopathology of many of these syndromes and more specifically to determine whether each manifestation can be attributed directly to the systemic disease or is a comorbidity. This goal requires improvement in imaging modalities and discovery of new biomarkers such as autoantibodies.

The rarity of these syndromes poses an impediment to the conduction of large randomized trials, concerning adequate management; currently, most treatment suggestions are largely empirical or based on small case series. With an improved understanding of pathophysiology, better-designed trials comprising a homogenous population will be highly informative.

The continuous emergence of new biological agents for the treatment of systemic autoimmune disorders offers new possibilities and creates the necessity for evaluation of these therapeutic options in patients with primary neurological manifestations. At the same time, novel agents will also emerge with a focus on neurological autoimmunity. It will be a great challenge in the future to select, for each individual patient, between "systemic" therapies or "organ-specific" therapies, or a combination of both. At the same time, vigilance is and will be required as some of these agents may have severe side effects, even causing secondary autoimmune events.

\section{Compliance with Ethical Standards}

Required Author Forms Disclosure forms provided by the authors are available with the online version of this article.

\section{References}

1. Hanly JG, Urowitz MB, Su L, et al. Prospective analysis of neuropsychiatric events in an international disease inception cohort of patients with systemic lupus erythematosus. Ann Rheum Dis 2010;69:529-535

2. Sofat N, Malik O, Higgens CS. Neurological involvement in patients with rheumatic disease. QJM 2006;99:69—79

3. Cikes N. Central nervous system involvement in systemic connective tissue diseases. Clin Neurol Neurosurg 2006;108:311-317

4. The American College of Rheumatology nomenclature and case definitions for neuropsychiatric lupus syndromes. Arthritis Rheum 1999;42:599-608

5. Bertsias GK, Boumpas DT. Pathogenesis, diagnosis and management of neuropsychiatric SLE manifestations. Nat Rev Rheumatol 2010;6:358-367

6. Ainiala H, Hietaharju A, Loukkola J, et al. Validity of the new American College of Rheumatology criteria for neuropsychiatric lupus syndromes: a population-based evaluation. Arthritis Rheum 2001;45:419-423

7. Hanly JG, McCurdy G, Fougere L, Douglas JA, Thompson K. Neuropsychiatric events in systemic lupus erythematosus: attribution and clinical significance. J Rheumatol 2004;31:2156-2162

8. Ramos-Remus C, Duran-Barragan S, Castillo-Ortiz JD. Beyond the joints: neurological involvement in rheumatoid arthritis. Clin Rheumatol 2012;31:1-12

9. Illei GG, Austin HA, Crane M, et al. Combination therapy with pulse cyclophosphamide plus pulse methylprednisolone improves 
long-term renal outcome without adding toxicity in patients with lupus nephritis. Ann Intern Med 2001;135:248-257

10. Wilke WS. Methotrexate use in miscellaneous inflammatory diseases. Rheum Dis Clin North Am 1997;23:855-882

11. Dalakas MC, Illa I, Dambrosia JM, et al. A controlled trial of highdose intravenous immune globulin infusions as treatment for dermatomyositis. N Engl J Med 1993;329:1993-2000

12. Neuwelt CM. The role of plasmapheresis in the treatment of severe central nervous system neuropsychiatric systemic lupus erythematosus. Ther Apher Dial 2003;7:173-182

13. Elliott MJ, Maini RN, Feldmann M, et al. Randomised doubleblind comparison of chimeric monoclonal antibody to tumour necrosis factor alpha (cA2) versus placebo in rheumatoid arthritis. Lancet 1994;344:1105-1110

14. Melikoglu M, Fresko I, Mat C, et al. Short-term trial of etanercept in Behcet's disease: a double blind, placebo controlled study. J Rheumatol 2005;32:98-105

15. Russell E, Luk F, Manocha S, Ho T, O'Connor C, Hussain H. Long term follow-up of infliximab efficacy in pulmonary and extra-pulmonary sarcoidosis refractory to conventional therapy. Semin Arthritis Rheum 2013;43:119-124

16. Emery P, Keystone E, Tony HP, et al. IL-6 receptor inhibition with tocilizumab improves treatment outcomes in patients with rheumatoid arthritis refractory to anti-tumour necrosis factor biologicals: results from a 24-week multicentre randomised placebo-controlled trial. Ann Rheum Dis 2008;67:1516-1523

17. Furie R, Petri M, Zamani O, et al. A phase III, randomized, placebocontrolled study of belimumab, a monoclonal antibody that inhibits B lymphocyte stimulator, in patients with systemic lupus erythematosus. Arthritis Rheum 2011;63:3918-3930

18. Armstrong DJ, McCarron MT, Wright GD. SLE-associated transverse myelitis successfully treated with Rituximab (anti-CD20 monoclonal antibody). Rheumatol Int 2006;26:771-772

19. Shapiro LS, Farrell J, Borhani Haghighi A. Tocilizumab treatment for neuro-Behcet's disease, the first report. Clin Neurol Neurosurg 2012;114:297-298

20. Birnbaum J. Peripheral nervous system manifestations of Sjogren syndrome: clinical patterns, diagnostic paradigms, etiopathogenesis, and therapeutic strategies. Neurologist 2010;16:287-297

21. Mayer M, Cerovec M, Rados M, Cikes N. Antiphospholipid syndrome and central nervous system. Clin Neurol Neurosurg 2010;112:602-608

22. Bertsias GK, Ioannidis JP, Aringer M, et al. EULAR recommendations for the management of systemic lupus erythematosus with neuropsychiatric manifestations: report of a task force of the EULAR standing committee for clinical affairs. Ann Rheum Dis 2010;69:2074-2082

23. Hanly JG, Urowitz MB, Su L, et al. Seizure disorders in systemic lupus erythematosus results from an international, prospective, inception cohort study. Ann Rheum Dis 2012;71:1502-1509

24. Jeltsch-David H, Muller S. Neuropsychiatric systemic lupus erythematosus: pathogenesis and biomarkers. Nat Rev Neurol 2014; 10:579-596

25. Milstone AM, Meyers K, Elia J. Treatment of acute neuropsychiatric lupus with intravenous immunoglobulin (IVIG): a case report and review of the literature. Clin Rheumatol 2005;24:394-397

26. Narvaez J, Rios-Rodriguez V, de la Fuente D, et al. Rituximab therapy in refractory neuropsychiatric lupus: current clinical evidence. Semin Arthritis Rheum 2011;41:364-372

27. Zouali M, Uy EA. Belimumab therapy in systemic lupus erythematosus. BioDrugs: clinical immunotherapeutics, Biopharmaceuticals Gene Ther 2013;27:225-235

28. Kampylafka EI, Alexopoulos H, Kosmidis ML, et al. Incidence and prevalence of major central nervous system involvement in systemic lupus erythematosus: a 3-year prospective study of 370 patients. PLoS One 2013;8:e55843

29. Baizabal-Carvallo JF, Alonso-Juarez M, Koslowski M. Chorea in systemic lupus erythematosus. J Clin Rheumatol: Pract Rep Rheum Musculoskelet Dis 2011;17:69-72

30. Birnbaum J, Petri M, Thompson R, Izbudak I, Kerr D. Distinct subtypes of myelitis in systemic lupus erythematosus. Arthritis Rheum 2009;60:3378-3387

31. Pittock SJ, Lennon VA, de Seze J, et al. Neuromyelitis optica and non organ-specific autoimmunity. Arch Neurol 2008;65:78-83

32. Kovacs B, Lafferty TL, Brent LH, DeHoratius RJ. Transverse myelopathy in systemic lupus erythematosus: an analysis of 14 cases and review of the literature. Ann Rheum Dis 2000;59:120 124

33. D'Cruz DP, Mellor-Pita S, Joven B, et al. Transverse myelitis as the first manifestation of systemic lupus erythematosus or lupuslike disease: good functional outcome and relevance of antiphospholipid antibodies. J Rheumatol 2004;31:280-285

34. Vina ER, Fang AJ, Wallace DJ, Weisman MH. Chronic inflammatory demyelinating polyneuropathy in patients with systemic lupus erythematosus: prognosis and outcome. Semin Arthritis Rheum 2005;35:175-184

35. Fanouriakis A, Boumpas DT, Bertsias GK. Pathogenesis and treatment of CNS lupus. Curr Opin Rheumatol 2013;25:577-583

36. Gaber W, Ezzat Y, El Fayoumy NM, Helmy H, Mohey AM. Detection of asymptomatic cranial neuropathies in patients with systemic lupus erythematosus and their relation to antiribosomal $\mathrm{P}$ antibody levels and disease activity. Clin Rheumatol 2014;33: 1459-1466

37. Dalakas MC. Advances in the diagnosis, pathogenesis and treatment of CIDP. Nat Rev Neurol 2011;7:507-517

38. Hughes RA, Donofrio P, Bril V, et al. Intravenous immune globulin ( $10 \%$ caprylate-chromatography purified) for the treatment of chronic inflammatory demyelinating polyradiculoneuropathy (ICE study): a randomised placebo-controlled trial. Lancet Neurol 2008;7:136-144

39. Mukhtyar C, Guillevin L, Cid MC, et al. EULAR recommendations for the management of primary small and medium vessel vasculitis. Ann Rheum Dis 2009;68:310-317

40. Ntatsaki E, Carruthers D, Chakravarty K, et al. BSR and BHPR guideline for the management of adults with ANCA-associated vasculitis. Rheumatology (Oxford) 2014;53:2306-2309

41. Kosmidis ML, Koutsogeorgopoulou L, Alexopoulos H, et al. Reduction of Intraepidermal Nerve Fiber Density (IENFD) in the skin biopsies of patients with fibromyalgia: a controlled study. J Neurol Sci 2014;347:143-147

42. Dalakas MC. Inflammatory muscle diseases. N Engl J Med 2015;372:1734-1747

43. Oddis CV, Reed AM, Aggarwal R, et al. Rituximab in the treatment of refractory adult and juvenile dermatomyositis and adult polymyositis: a randomized, placebophase trial. Arthritis Rheum 2013;65:314-324

44. Sussman J, Farrugia ME, Maddison P, Hill M, Leite MI, HiltonJones D. Myasthenia gravis: association of British Neurologists' management guidelines. Pract Neurol 2015;15:199-206

45. Carecchio M, Cantello R, Comi C. Revisiting the molecular mechanism of neurological manifestations in antiphospholipid syndrome: beyond vascular damage. J Immunol Res 2014;2014: 239398

46. Lee DM, Jeon HS, Yoo WH. Transverse myelitis in a patient with primary antiphospholipid syndrome. Yonsei Med J 2003;44:323327

47. Rodrigues CE, de Carvalho JF. Clinical, radiologic, and therapeutic analysis of 14 patients with transverse myelitis associated with antiphospholipid syndrome: report of 4 cases and review of the literature. Semin Arthritis Rheum 2011;40:349-357 
48. Chapman J, Cohen-Armon M, Shoenfeld Y, Korczyn AD. Antiphospholipid antibodies permeabilize and depolarize brain synaptoneurosomes. Lupus 1999;8:127-133

49. Ruiz-Irastorza G, Cuadrado MJ, Ruiz-Arruza I, et al. Evidencebased recommendations for the prevention and long-term management of thrombosis in antiphospholipid antibody-positive patients: report of a task force at the 13th International Congress on antiphospholipid antibodies. Lupus 2011;20:206-218

50. Grika EP, Ziakas PD, Zintzaras E, Moutsopoulos HM, Vlachoyiannopoulos PG. Morbidity, mortality, and organ damage in patients with antiphospholipid syndrome. J Rheumatol 2012;39:516-523

51. Lockshin MD, Erkan D. Treatment of the antiphospholipid syndrome. N Engl J Med 2003;349:1177-1179

52. Rubenstein E, Arkfeld DG, Metyas S, Shinada S, Ehresmann S, Liebman HA. Rituximab treatment for resistant antiphospholipid syndrome. J Rheumatol 2006;33:355-357

53. Agildere AM, Tutar NU, Yucel E, Coskun M, Benli S, Aydin P. Pachymeningitis and optic neuritis in rheumatoid arthritis: MRI findings. Br J Radiol 1999; 72:404-407

54. Catananti C, Mastropaolo S, Calabrese C, Silveri MC, Onder G. A case of normal-pressure hydrocephalus associated with rheumatoid arthritis. Aging Clin Exp Res 2010;22:189-191

55. Ikeda $\mathrm{K}$, Takazawa $\mathrm{T}$, Ito $\mathrm{H}$, et al. Rheumatoid leptomeningitis: radiological alteration of cerebral hypoperfusion and subarachnoid lesions. Intern Med 2010;49:1911-1916

56. Inan AS, Masatlioglu S, Ozyurek SC, Engin D, Erdem I. Unusual central nervous system involvement of rheumatoid arthritis: successful treatment with steroid and azathioprine. Rheumatol Int 2011;31:1383-1385

57. Mrabet D, Meddeb N, Ajlani H, Sahli H, Sellami S. Cerebral vasculitis in a patient with rheumatoid arthritis. Joint Bone Spine 2007;74:201-204

58. Schmid L, Muller M, Treumann T, et al. Induction of complete and sustained remission of rheumatoid pachymeningitis by rituximab. Arthritis Rheum 2009;60:1632-1634

59. Kato T, Hoshi K, Sekijima Y, et al. Rheumatoid meningitis: an autopsy report and review of the literature. Clin Rheumatol 2003;22:475-480

60. Starosta MA, Brandwein SR. Clinical manifestations and treatment of rheumatoid pachymeningitis. Neurology 2007;68:10791080

61. Yucel AE, Kart H, Aydin P, et al. Pachymeningitis and optic neuritis in rheumatoid arthritis: successful treatment with cyclophosphamide. Clin Rheumatol 2001;20:136-139

62. Chou RC, Henson JW, Tian D, Hedley-Whyte ET, Reginato AM. Successful treatment of rheumatoid meningitis with cyclophosphamide but not infliximab. Ann Rheum Dis 2006;65:1114-1116

63. Karam NE, Roger L, Hankins LL, Reveille JD. Rheumatoid nodulosis of the meninges. J Rheumatol 1994;21:1960-1963

64. Tsegaye M, Bassi S, Ashpole RD. Extradural spinal cord compression by rheumatoid nodule. Br J Neurosurg 2003;17:255-257

65. Koivikko MP, Koskinen SK. MRI of cervical spine injuries complicating ankylosing spondylitis. Skeletal Radiol 2008;37:813819

66. Santavirta SS, Konttinen YT. Atlantoaxial subluxation and spinal cord compression in psoriatic arthropathy. Ann Rheum Dis $1988 ; 47: 173$

67. Louthrenoo W, Zager EL, Freundlich B, Zurier RB. Intravenous corticosteroid therapy of cervical cord compression in rheumatoid arthritis. Clin Exp Rheumatol 1992;10:173-175

68. Cornec D, Devauchelle Pensec V, Joulin SJ, Saraux A. Dramatic efficacy of infliximab in cauda equina syndrome complicating ankylosing spondylitis. Arthritis Rheum 2009;60:1657-1660

69. Rath JJ, Ronday HK, Wirtz PW. Acute transverse myelitis in psoriatic arthritis. J Neurol 2010;257:457-458
70. Guilloton L, Flocard F, Dubourg P, Drouet A, Ribot C. [Polyradicular lesion revealing ankylosing spondylarthritis]. Rev Med Interne 1999;20:158-159

71. Kotil K, Yavasca P. Lumbar radiculopathy in ankylosing spondylitis with dural ectasia. J Clin Neurosci 2007;14:981-983

72. Scott DG, Bacon PA. Intravenous cyclophosphamide plus methylprednisolone in treatment of systemic rheumatoid vasculitis. Am J Med 1984;76:377-384

73. Richter C, Wanke L, Steinmetz J, Reinhold-Keller E, Gross WL. Mononeuritis secondary to rheumatoid arthritis responds to etanercept. Rheumatology (Oxford) 2000;39:1436-1437

74. Unger L, Kayser M, Nusslein HG. Successful treatment of severe rheumatoid vasculitis by infliximab. Ann Rheum Dis 2003;62: 587-588

75. Jarrett SJ, Cunnane G, Conaghan PG, et al. Anti-tumor necrosis factor-alpha therapy-induced vasculitis: case series. J Rheumatol 2003;30:2287-2291

76. Iijima T, Suwabe T, Sumida K, et al. Tocilizumab improves systemic rheumatoid vasculitis with necrotizing crescentic glomerulonephritis. Mod Rheumatol 2015;25:138-142

77. Fujii W, Kohno M, Ishino H, et al. The rapid efficacy of abatacept in a patient with rheumatoid vasculitis. Mod Rheumatol 2012;22: 630-634

78. Katz-Agranov N, Khattri S, Zandman-Goddard G. The role of intravenous immunoglobulins in the treatment of rheumatoid arthritis. Autoimmun Rev 2015

79. Makol A, Matteson EL, Warrington KJ. Rheumatoid vasculitis: an update. Curr Opin Rheumatol 2015;27:63-70

80. Massara A, Bonazza S, Castellino G, et al. Central nervous system involvement in Sjogren's syndrome: unusual, but not unremarkable-clinical, serological characteristics and outcomes in a large cohort of Italian patients. Rheumatology (Oxford) 2010;49:1540 1549

81. Morreale M, Marchione P, Giacomini P, et al. Neurological involvement in primary Sjogren syndrome: a focus on central nervous system. PLoS One 2014;9:e84605

82. Delalande S, de Seze J, Fauchais AL, et al. Neurologic manifestations in primary Sjogren syndrome: a study of 82 patients. Medicine (Baltimore) 2004;83:280-291

83. Teixeira F, Moreira I, Silva AM, Vasconcelos C, Farinha F, Santos E. Neurological involvement in Primary Sjogren Syndrome. Acta Reumatol Port 2013;38:29-36

84. Gerraty RP, McKelvie PA, Byrne E. Aseptic meningoencephalitis in primary Sjogren's syndrome. Response to plasmapheresis and absence of CNS vasculitis at autopsy. Acta Neurol Scand 1993;88: 309-311

85. Akasbi M, Berenguer J, Saiz A, et al. White matter abnormalities in primary Sjogren syndrome. QJM 2012;105:433-443

86. Mekinian A, Ravaud P, Larroche C, et al. Rituximab in central nervous system manifestations of patients with primary Sjogren's syndrome: results from the AIR registry. Clin Exp Rheumatol 2012;30:208-212

87. Ramos-Casals M, Tzioufas AG, Stone JH, Siso A, Bosch X. Treatment of primary Sjogren syndrome: a systematic review. JAMA 2010;304:452-460

88. Wu JJ, Carsons SE. Management of extraglandular manifestations of primary Sjogren's syndrome. Oral Maxillofac Surg Clin North Am 2014;26:101-109

89. Jamilloux Y, Magy L, Hurtevent JF, et al. Immunological profiles determine neurological involvement in Sjogren's syndrome. Eur J Intern Med 2014;25:177-181

90. Pavlakis PP, Alexopoulos H, Kosmidis ML, et al. Peripheral neuropathies in Sjogren syndrome: a new reappraisal. J Neurol neurosurgery Psychiatr 2011;82:798-802 
91. Pavlakis PP, Alexopoulos H, Kosmidis ML, et al. Peripheral neuropathies in Sjogren's syndrome: a critical update on clinical features and pathogenetic mechanisms. J Autoimmun 2012;39:27-33

92. Kuntzer T, Antoine JC, Steck AJ. Clinical features and pathophysiological basis of sensory neuronopathies (ganglionopathies). Muscle Nerve 2004;30:255-268

93. Takahashi Y, Takata T, Hoshino M, Sakurai M, Kanazawa I. Benefit of IVIG for long-standing ataxic sensory neuronopathy with Sjogren's syndrome. IV immunoglobulin. Neurology 2003;60:503-505

94. Caroyer JM, Manto MU, Steinfeld SD. Severe sensory neuronopathy responsive to infliximab in primary Sjogren's syndrome. Neurology 2002;59:1113-1114

95. Chen WH, Yeh JH, Chiu HC. Plasmapheresis in the treatment of ataxic sensory neuropathy associated with Sjogren's syndrome. European Neurol 2001;45:270-274

96. Imrich R, Vernino S, Eldadah BA, Holmes C, Goldstein DS. Autoimmune autonomic ganglionopathy: treatment by plasma exchanges andrituximab. Clin Auton Res 2009;19:259-262

97. Yamada S, Mori K, Matsuo K, Inukai A, Kawagashira Y, Sobue G. Interferon alfa treatment for Sjogren's syndrome associated neuropathy. J Neurol Neurosurg Psychiatry 2005;76:576-578

98. Mori K, Iijima M, Koike H, et al. The wide spectrum of clinical manifestations in Sjogren's syndrome-associated neuropathy. Brain 2005;128:2518-2534

99. Schaublin GA, Michet CJ, Jr., Dyck PJ, Burns TM. An update on the classification and treatment of vasculitic neuropathy. Lancet Neurol 2005;4:853-865

100. Sene D, Jallouli M, Lefaucheur JP, et al. Peripheral neuropathies associated with primary Sjogren syndrome: immunologic profiles of nonataxic sensory neuropathy and sensorimotor neuropathy. Medicine (Baltimore) 2011;90:133-138

101. Mekinian A, Ravaud P, Hatron PY, et al. Efficacy of rituximab in primary Sjogren's syndrome with peripheral nervous system involvement: results from the AIR registry. Ann Rheum Dis 2012;71:84-87

102. Attal N, Cruccu G, Baron R, et al. EFNS guidelines on the pharmacological treatment of neuropathic pain: 2010 revision. Eur J Neurol 2010;17:1113-e1188

103. Moulin D, Boulanger A, Clark AJ, et al. Pharmacological management of chronic neuropathic pain: revised consensus statement from the Canadian Pain Society. Pain Res Manag 2014;19:328335

104. Botez SA, Herrmann DN. Prolonged remission of a demyelinating neuropathy in a patient with lymphoma and Sjogren's syndrome after Rituximab therapy. J Clin Neuromuscul Dis 2010;11:127131

105. Wakasugi D, Kato T, Gono T, et al. Extreme efficacy of intravenous immunoglobulin therapy for severe burning pain in a patient with small fiber neuropathy associated with primary Sjogren's syndrome. Mod Rheumatol 2009;19:437-440

106. Govoni M, Bajocchi G, Rizzo N, et al. Neurological involvement in primary Sjogren's syndrome: clinical and instrumental evaluation in a cohort of Italian patients. Clin Rheumatol 1999;18:299303

107. Amaral TN, Peres FA, Lapa AT, Marques-Neto JF, Appenzeller S. Neurologic involvement in scleroderma: a systematic review. Semin Arthritis Rheum 2013;43:335-347

108. Canas CA, Orozco JL, Paredes AC, Bonilla-Abadia F. Successful treatment of hemifacial myokymia and dystonia associated to linear scleroderma "en coup de sabre" with repeated botox injections. Case Rep Med 2012;2012:691314

109. Verhelst HE, Beele H, Joos R, Vanneuville B, Van Coster RN. Hippocampal atrophy and developmental regression as first sign of linear scleroderma "en coup de sabre". Eur J Paediatr Neurol: EJPN: Off J Eur Paediatr Neurol Soc 2008;12:508-511
110. Holland KE, Steffes B, Nocton JJ, Schwabe MJ, Jacobson RD, Drolet BA. Linear scleroderma en coup de sabre with associated neurologic abnormalities. Pediatrics 2006;117:e132-136

111. Obermoser G, Pfausler BE, Linder DM, Sepp NT. Scleroderma en coup de sabre with central nervous system and ophthalmologic involvement: treatment of ocular symptoms with interferon gamma. J Am Acad Dermatol 2003;49:543-546

112. Lima IV, Galrao LA, Maia TS, Santiago MB. Spinal cord compression by ectopic calcinosis in scleroderma. Clin Exp Rheumatol 2005;23:704-706

113. Trebst C, Jarius S, Berthele A, et al. Update on the diagnosis and treatment of neuromyelitis optica: recommendations of the Neuromyelitis Optica Study Group (NEMOS). J Neurol 2014;261:1-16

114. Khan I, Watts RA. Classification of ANCA-associated vasculitis. Curr Rheumatol Rep 2013;15:383

115. Rossi CM, Di Comite G. The clinical spectrum of the neurological involvement in vasculitides. J Neurol Sci 2009;285:13-21

116. Cantini F, Niccoli L, Nannini C, Bertoni M, Salvarani C. Diagnosis and treatment of giant cell arteritis. Drugs Aging 2008;25:281-297

117. Salvarani C, Pipitone N, Versari A, Hunder GG. Clinical features of polymyalgia rheumatica and giant cell arteritis. Nat Rev Rheumatol 2012;8:509-521

118. Hunder GG, Bloch DA, Michel BA, et al. The American College of Rheumatology 1990 criteria for the classification of giant cell arteritis. Arthritis Rheum 1990;33:1122-1128

119. Nagel MA, Bennett JL, Khmeleva N, et al. Multifocal VZV vasculopathy with temporal artery infection mimics giant cell arteritis. Neurology 2013;80:2017-2021

120. Nagel MA, Khmeleva N, Boyer PJ, Choe A, Bert R, Gilden D. Varicella zoster virus in the temporal artery of a patient with giant cell arteritis. J Neurol Sci 2013;335:228-230

121. Dasgupta B, Borg FA, Hassan N, et al. BSR and BHPR guidelines for the management of giant cell arteritis. Rheumatology (Oxford) 2010;49:1594-1597

122. Mukhtyar C, Guillevin L, Cid MC, et al. EULAR recommendations for the management of large vessel vasculitis. Ann Rheum Dis 2009;68:318-323

123. Kerr GS, Hallahan CW, Giordano J, et al. Takayasu arteritis. Ann Intern Med 1994;120:919-929

124. Gupta R, Kumar S. Relapsing spinal cord and cranial nerve syndromes in Takayasu's arteritis. J Assoc Phys India 1989;37:537539

125. Nair KR, Bhaskaran R, Retnakumari S, Madhusoodana M. Ischemic myelopathy in Takayasu's disease. J Assoc Phys India 1985;33:735-736

126. Hoffman GS, Merkel PA, Brasington RD, Lenschow DJ, Liang P. Anti-tumor necrosis factor therapy in patients with difficult to treat Takayasu arteritis. Arthritis Rheum 2004;50:2296-2304

127. Molloy ES, Langford CA, Clark TM, Gota CE, Hoffman GS. Anti-tumour necrosis factor therapy in patients with refractory Takayasu arteritis: long-term follow-up. Ann Rheum Dis 2008;67:1567-1569

128. Ernst D, Greer M, Stoll M, Meyer-Olson D, Schmidt RE, Witte T. Remission achieved in refractory advanced takayasu arteritis using rituximab. Case Rep Rheumatol 2012;2012:406963

129. Unizony S, Arias-Urdaneta L, Miloslavsky E, et al. Tocilizumab for the treatment of large-vessel vasculitis (giant cell arteritis, Takayasu arteritis) and polymyalgia rheumatica. Arthritis Res 2012;64:1720-1729

130. Mencacci NE, Bersano A, Cinnante CM, et al. Intracerebral haemorrhage, a possible presentation in Churg-Strauss syndrome: case report and review of the literature. J Neurol Sci 2011;301:107-111

131. De Luna G, Terrier B, Kaminsky P, et al. Central nervous system involvement of granulomatosis with polyangiitis: clinical- 
radiological presentation distinguishes different outcomes. Rheumatology (Oxford) 2015;54:424-432

132. Padovano I, Pazzola G, Pipitone N, Cimino L, Salvarani C. Anterior ischaemic optic neuropathy in eosinophilic granulomatosis with polyangiitis (Churg-Strauss syndrome): a case report and review of the literature. Clin Exp Rheumatol 2014;32:S62-65

133. Suppiah R, Hadden RD, Batra R, et al. Peripheral neuropathy in ANCA-associated vasculitis: outcomes from the European Vasculitis Study Group trials. Rheumatology (Oxford) 2011;50: 2214-2222

134. Stone JH, Merkel PA, Spiera R, et al. Rituximab versus cyclophosphamide for ANCA-associated vasculitis. N Engl J Med 2010;363:221-232

135. Just SA, Knudsen JB, Nielsen MK, Junker P. Wegener's granulomatosis presenting with pachymeningitis: clinical and imaging remission by rituximab. ISRN Rheumatol 2011;2011:608942

136. Memet B, Rudinskaya A, Krebs T, Oelberg D. Wegener granulomatosis with massive intracerebral hemorrhage: remission of disease in response to rituximab. J Clin Rheumatol: Pract Rep Rheum Musculoskelet Dis 2005;11:314-318

137. Silva-Fernandez L, Loza E, Martinez-Taboada VM, et al. Biological therapy for systemic vasculitis: a systematic review. Semin Arthritis Rheum 2014;43:542-557

138. Kahn JE, Grandpeix-Guyodo C, Marroun I, et al. Sustained response to mepolizumab in refractory Churg-Strauss syndrome. J Allergy Clin Immunol 2010;125:267-270

139. Kim S, Marigowda G, Oren E, Israel E, Wechsler ME. Mepolizumab as a steroid-sparing treatment option in patients with Churg-Strauss syndrome. J Allergy Clin Immunol 2010;125:1336-1343

140. Farah S, Al-Shubaili A, Montaser A, et al. Behcet's syndrome: a report of 41 patients with emphasis on neurological manifestations. J Neurol Neurosurg Psychiatry 1998;64:382-384

141. Tursen U, Gurler A, Boyvat A. Evaluation of clinical findings according to sex in 2313 Turkish patients with Behcet's disease. Int J Dermatol 2003;42:346-351

142. Al-Araji A, Kidd DP. Neuro-Behcet's disease: epidemiology, clinical characteristics, and management. Lancet Neurol 2009;8:192204

143. Al-Araji A, Sharquie K, Al-Rawi Z. Prevalence and patterns of neurological involvement in Behcet's disease: a prospective study from Iraq. J Neurol neurosurg Psychiatry 2003;74:608-613

144. Joseph FG, Scolding NJ. Neuro-Behcet's disease in Caucasians: a study of 22 patients. Eur J Neurol 2007;14:174-180

145. Akman-Demir G, Serdaroglu P, Tasci B. Clinical patterns of neurological involvement in Behcet's disease: evaluation of 200 patients. The Neuro-Behcet Study Group. Brain 1999;122 ( Pt 11): 2171-2182

146. Wechsler B, Vidailhet M, Piette JC, et al. Cerebral venous thrombosis in Behcet's disease: clinical study and long-term follow-up of 25 cases. Neurology 1992;42:614-618

147. Kidd D. Neurological complications of Behcet's syndrome. Curr Neurol Neurosci Rep 2012;12:675-679

148. Ait Ben Haddou EH, Imounan F, Regragui W, et al. Neurological manifestations of Behcet's disease: evaluation of 40 patients treated by cyclophosphamide. Rev Neurol (Paris) 2012;168:344-349

149. Caso F, Costa L, Rigante D, et al. Biological treatments in Behcet's disease: beyond anti-TNF therapy. Mediators of inflammation 2014;2014:107421

150. Hatemi G, Silman A, Bang D, et al. EULAR recommendations for the management of Behcet disease. Ann Rheum Dis 2008;67: $1656-1662$

151. Hatemi G, Silman A, Bang D, et al. Management of Behcet disease: a systematic literature review for the European League Against Rheumatism evidence-based recommendations for the management of Behcet disease. Ann Rheum Dis 2009;68:15281534

152. Schotland DL, Wolf SM, White HH, Dubin HV. Neurologic aspects of Behcet's disease. Case report and review of the literature. Am J Med 1963;34:544-553

153. Abalos-Medina GM, Sanchez-Cano D, Ruiz-Villaverde G, RuizVillaverde R, Quirosa Flores S, Raya Alvarez E. Successful use of infliximab in a patient with neuro-Behcet's disease. Int J Rheum Dis 2009;12:264-266

154. Alty JE, Monaghan TM, Bamford JM. A patient with neuroBehcet's disease is successfully treated with etanercept: further evidence for the value of TNFalpha blockade. Clin Neurol Neurosurg 2007;109:279-281

155. Kikuchi H, Aramaki K, Hirohata S. Effect of infliximab in progressive neuro-Behcet's syndrome. J Neurol Sci 2008;272:99-105

156. Pipitone N, Olivieri I, Padula A, et al. Infliximab for the treatment of Neuro-Behcet's disease: a case series and review of the literature. Arthritis Rheum 2008;59:285-290

157. Borhani Haghighi A, Safari A, Nazarinia MA, Habibagahi Z, Shenavandeh S. Infliximab for patients with neuro-Behcet's disease: case series and literature review. Clin Rheumatol 2011;30: $1007-1012$

158. Cantarini L, Vitale A, Scalini P, et al. Anakinra treatment in drugresistant Behcet's disease: a case series. Clin Rheumatol 2013

159. Atasoy HT, Tunc TO, Unal AE, et al. Peripheral nervous system involvement in patients with Behcet disease. Neurologist 2007;13: 225-230

160. Takeuchi A, Kodama M, Takatsu M, Hashimoto T, Miyashita H Mononeuritis multiplex in incomplete Behcet's disease: a case report and the review of the literature. Clin Rheumatol 1989;8: 375-380

161. Shugaiv E, Kiyat-Atamer A, Tuzun E, et al. Coexistence of Guillain-Barre syndrome and Behcet's disease. Clin Exp Rheumatol 2013;31:88-89

162. Chau SY, Mok CC. Factors predictive of corticosteroid psychosis in patients with systemic lupus erythematosus. Neurology 2003;61:104-107

163. Kenna HA, Poon AW, de los Angeles CP, Koran LM. Psychiatric complications of treatment with corticosteroids: review with case report. Psychiatry Clin Neurosci 2011;65:549-560

164. Schakman O, Gilson H, Thissen JP. Mechanisms of glucocorticoid-induced myopathy. J Endocrinol 2008;197:1-10

165. Dalakas MC. Inflammatory and toxic myopathies. Curr Opin Neurol Neurosurg 1992;5:645-654

166. Pereira RM, Freire de Carvalho J. Glucocorticoid-induced myopathy. Joint Bone Spine 2011;78:41-44

167. Granata G, Greco A, Iannella G, et al. Posterior reversible encephalopathy syndrome-Insight into pathogenesis, clinical variants and treatment approaches. Autoimmun Rev 2015

168. Mak A, Chan BP, Yeh IB, et al. Neuropsychiatric lupus and reversible posterior leucoencephalopathy syndrome: a challenging clinical dilemma. Rheumatology (Oxford) 2008;47:256-262

169. Min L, Zwerling J, Ocava LC, Chen IH, Putterman C. Reversible posterior leukoencephalopathy in connective tissue diseases. Semin Arthritis Rheum 2006;35:388-395

170. Fujieda Y, Kataoka H, Odani T, et al. Clinical features of reversible posterior leukoencephalopathy syndrome in patients with systemic lupus erythematosus. Mod Rheumatol 2011;21:276-281

171. Primavera A, Audenino D, Mavilio N, Cocito L. Reversible posterior leucoencephalopathy syndrome in systemic lupus and vasculitis. Ann Rheum Dis 2001;60:534-537

172. Gordon C. Long-term complications of systemic lupus erythematosus. Rheumatology (Oxford) 2002;41:1095-1100

173. Brew BJ, Davies NW, Cinque P, Clifford DB, Nath A. Progressive multifocal leukoencephalopathy and other forms of JC virus disease. Nat Rev Neurol 2010;6:667-679 
174. Berger JR, Mucke L. Prolonged survival and partial recovery in AIDS-associated progressive multifocal leukoencephalopathy. Neurology 1988;38:1060-1065

175. Berger JR, Concha M. Progressive multifocal leukoencephalopathy: the evolution of a disease once considered rare. J Neurovirol 1995;1:5-18

176. Dang L, Dang X, Koralnik IJ, Todd PK. JC polyomavirus granule cell neuronopathy in a patient treated with rituximab. JAMA Neurol 2014;71:487-489

177. Graff-Radford J, Robinson MT, Warsame RM, Matteson EL, Eggers SD, Keegan BM. Progressive multifocal leukoencephalopathy in a patient treated with etanercept. Neurologist 2012;18:85-87

178. Langer-Gould A, Atlas SW, Green AJ, Bollen AW, Pelletier D. Progressive multifocal leukoencephalopathy in a patient treated with natalizumab. N Engl J Med 2005;353:375-381

179. Pavlovic AM, Bonaci-Nikolic B, Kozic D, et al. Progressive multifocal leukoencephalopathy associated with mycophenolate mofetil treatment in a woman with lupus and CD4+ T-lymphocyte deficiency. Lupus 2012;21:100-102

180. Schwab N, Ulzheimer JC, Fox RJ, et al. Fatal PML associated with efalizumab therapy: insights into integrin alphaLbeta2 in JC virus control. Neurology 2012;78:458-467; discussion 465

181. van Oosten BW, Killestein J, Barkhof F, Polman CH, Wattjes MP. PML in a patient treated with dimethyl fumarate from a compounding pharmacy. N Engl J Med 2013;368:1658-1659

182. Greenlee JE. Progressive multifocal leucoencephalopathy in the era of natalizumab: a review and discussion of the implications. Int MS J 2006;13:100-107

183. Bloomgren G, Richman S, Hotermans C, et al. Risk of natalizumab-associated progressive multifocal leukoencephalopathy. N Engl J Med 2012;366:1870-1880

184. Rudick RA, O'Connor PW, Polman CH, et al. Assessment of JC virus DNA in blood and urine from natalizumab-treated patients. Ann Neurol 2010;68:304-310

185. Du Pasquier RA, Kuroda MJ, Zheng Y, Jean-Jacques J, Letvin NL, Koralnik IJ. A prospective study demonstrates an association between JC virus-specific cytotoxic T lymphocytes and the early control of progressive multifocal leukoencephalopathy. Brain 2004;127:1970-1978
186. Chalkias S, Dang X, Bord E, et al. JC virus reactivation during prolonged natalizumab monotherapy for multiple sclerosis. Ann Neurol 2014;75:925-934

187. Gheuens S, Smith DR, Wang X, Alsop DC, Lenkinski RE, Koralnik IJ. Simultaneous PML-IRIS after discontinuation of natalizumab in a patient with MS. Neurology 2012;78:1390-1393

188. Molloy ES, Calabrese LH. Progressive multifocal leukoencephalopathy: a national estimate of frequency in systemic lupus erythematosus and other rheumatic diseases. Arthritis Rheum 2009;60:3761-3765

189. Brandao M, Damasio J, Marinho A, et al. Systemic lupus erythematosus, progressive multifocal leukoencephalopathy, and T-CD4+ lymphopenia. Clin Rev Allergy Immunol 2012;43:302-307

190. Faillace C, de Almeida JR, de Carvalho JF. Optic neuritis after infliximab therapy. Rheumatol Int 2013;33:1101-1103

191. Matsumoto T, Nakamura I, Miura A, Momoyama G, Ito K. Newonset multiple sclerosis associated with adalimumab treatment in rheumatoid arthritis: a case report and literature review. Clin Rheumatol 2013;32:271-275

192. Mercieca C, Vella N, Borg AA. Demyelination during antiTNFalpha therapy for ankylosing spondylitis. Mod Rheumatol 2012;22:303-307

193. Seror R, Richez C, Sordet C, et al. Pattern of demyelination occurring during anti-TNF-alpha therapy: a French national survey. Rheumatology (Oxford) 2013;52:868-874

194. Theibich A, Dreyer L, Magyari M, Locht H. Demyelinizing neurological disease after treatment with tumor necrosis factor alphainhibiting agents in a rheumatological outpatient clinic: description of six cases. Clin Rheumatol 2014;33:719-723

195. Yagita M, Hamano T, Hatachi S, Fujita M. Peripheral neuropathies during biologic therapies. Mod Rheumatol 2013

196. Kaltsonoudis E, Zikou AK, Voulgari PV, Konitsiotis S, Argyropoulou MI, Drosos AA. Neurological adverse events in patients receiving anti-TNF therapy: a prospective imaging and electrophysiological study. Arthritis Res Ther 2014;16:R125

197. Caminero A, Comabella M, Montalban X. Tumor necrosis factor alpha (TNF-alpha), anti-TNF-alpha and demyelination revisited: an ongoing story. J Neuroimmunol 2011;234:1-6

198. Kaltsonoudis E, Voulgari PV, Konitsiotis S, Drosos AA. Demyelination and other neurological adverse events after antiTNF therapy. Autoimmun Rev 2014;13:54-5. 